\title{
Students' Assessment and Performance in Machine Shorthand: Basis on the Development of Instructional Materials
}

\author{
Ed Jesson G. Valiente, LPT, PhD \\ edjesson.valiente@1spu.edu.ph \\ Faculty Member, College of Buiness Mangement and Accountancy, Laguna State Polytechnic University, \\ Brgy. Bubukal, Sta. Cruz, Laguna, 4009, Philippines
}

\begin{abstract}
This research study was conducted to know the performance of the students in Machine shorthand. Many BSOA students find difficulty in Machine shorthand since they just met this subject in college. Unlike other subjects, they do not have an idea about it. BSOA students are having a hard time in dealing with Machine shorthand and it requires effort, attention, skill and focus to this matter.

The descriptive method was used as research design. Self-made questionnaire with a 5-point Likert scale was utilized to obtain the data needed in in terms of striking speed, reading comprehension and transcription ability. Pre-test and Post-test was executed to determine the performance in machine shorthand. Tools such as weighted mean, standard deviation and t-test was used to interpret the results. One hundred thirteen (113) students completed the survey instrument. This study revealed machine shorthand on students' knowledge is satisfactory and performance is moderately satisfactory. The conducted pre-test is less satisfactory with a total mean score of 11.805 and post test with a verbal interpretation of satisfactory. A significant difference to the assessment of Machine Shorthand to the students at 0.05 level of significance was found between knowledge and their performance which means the assessment of students' performance affects their knowledge on Machine Shorthand.
\end{abstract}

A development of instructional materials shall be proposed for the improvement of students' performance which include learn to operate the Machine shorthand through proper keyboard techniques and full understanding of the principles involved in learning.

Keywords: keyboard practice; reading comprehension; striking speed; sound pattern; transcription ability; word abbreviation

\section{Introduction}

Machine shorthand has been as old as the history of the human race of antiquity to modernity and conceived as profoundly dependable method of recording and communicating ideas as since then before the birth of Christ until this 21 st century internet high-technology advancement and transcription of ideas. It is the art of using a specialist Machine in order to write at very fast speeds very accurately. This is achieved by writing syllables, words or even entire phrases in a single hand motion.

More than ever, machine shorthand has become an important tool in business communication as well as in the long-established uses of reporting and personal writing, from court room transcripts and even within in classroom. 
Hibbard Performance based learning and assessment achieve a balanced approach by extending traditional fact and skill instruction. Performance based learning and assessment are not a curriculum design. Whereas you decide what to teach, performance-based learning and assessment constitute a better way to deliver your curriculum. Teachers do not have to give up units of study or favorite activities in a performancebased classroom. Because authentic tasks are rooted in curriculum, teachers can develop tasks based on what already works for them. Through this process, assignments become more authentic and more meaningful to students.

In Don Elger Theory of Performance (2011), current level of performance depends holistically on six components: context, level of knowledge, level of skills, level of identity, personal factors, and fixed factors. For that reason, the performance of students in their Machine shorthand subject is greatly affected by their level of knowledge, skills and other factors. Knowledge involves facts, information and concepts acquired by a person or group through experience or education. Students must have knowledge in order to understand lessons and if they understand their lessons, they can have better performance in Machine shorthand. Skill is also important in terms of performance. It describes specific actions that are used by individuals, groups or organizations in multiple types of performance. To perform is to take a complex series of actions that integrate skills and knowledge to produce a valuable result.

At first glance, a Machine shorthand looks like a regular keyboard. But once you will use it for shorthand, it is really difficult since there is no letter written on the keyboard. It is very far from a computer keyboard. It needs familiarization of strokes and also constant practice.

Office Administration students are expected to work in many establishments especially in courts as stenographers. But before dealing with those, Office Administration students must first learn, understand and have a good performance in Machine shorthand. They must acquire all the skills and motivations to achieve such goal.

\section{Methodology}

The researcher will use descriptive survey method in gathering and treating the data for this study. In the employment of this study in gathering and treating the data for this study. In the employment of this kind of research design, the researcher will observe thoroughly the population frame of the study through careful definition and specific delimitation in order to set the precise parameter for answering the discreteness of its characteristics.

Therefore, particular attention that will safeguard the data from the influence of bias by organizing and presenting them systematically so that valid and accurate conclusions will be drawn as a basis for viable recommendations therein Calmorin, et al. (2016). From the procedure discussed above, the researcher fully believes that descriptive method is appropriate for this kind of research undertaking.

A 35-item self-made questionnaire with a 5-point Likert scale was utilized to obtain the data needed in the study and Pre-test and Post-test to determine the performance of the students. Tools such as weighted mean, standard deviation and t-test was used to interpret the results. Weighted mean was used to determine the 
average levels of the variables, standard deviation to determine the relative importance of each quantity to the average and T-test to determine the relationship between them.

\section{Results and Discussion}

Table 1 presents the assessment level of students' knowledge in Machine shorthand in terms of sound pattern.

\begin{tabular}{lccc}
\hline \multicolumn{1}{c}{ Statements } & $\begin{array}{c}\text { Weighted } \\
\text { Mean }\end{array}$ & SD & Remarks \\
\hline 1. I am familiar with the sounds. & 3.92 & 0.64 & Often \\
2. I know how to use the symbol in sound pattern. & 3.80 & 0.68 & Often \\
3. I can memorize the sound. & 3.76 & 0.75 & Often \\
4. I can easily recognize the symbol of sounds. & 3.58 & 0.70 & Often \\
5. I can differentiate the sound pattern in every word. & 3.55 & 0.64 & Often \\
\hline
\end{tabular}

Grand Mean = 3.72

Population Standard Deviation $=0.5294$

Verbal Interpretation = Satisfactory

Legend:

$\begin{array}{llll}\text { Scale } & \text { Range } & \text { Remarks } & \text { Verbal Interpretation } \\ 5 & 4.20-5.00 & \text { Always } & \text { Very Satisfactory } \\ 4 & 3.40-4.19 & \text { Often } & \text { Satisfactory } \\ 3 & 2.60-3.39 & \text { Sometimes } & \text { Moderately Satisfactory } \\ 2 & 1.80-2.59 & \text { Rarely } & \text { Less Satisfactory } \\ 1 & 1.00-1.79 & \text { Never } & \text { Not Satisfactory }\end{array}$

The weighted mean of $\mathbf{3 . 7 2}$ has a standard deviation of 0.5294 with variance of 0.2803 indicating how the data scores are homogeneous to each other. The Skewness of 0.16 and a Kurtosis of -0.15 shows that the strategic priorities has a fairly symmetrical distribution with a sharp and central peak of score of 1 (minimum) and 4 (maximum) has a verbal interpretation of Satisfactory. Sound pattern was able to teach not only how to write full words in stenography, but how to write individual reusable parts of words to be used as building blocks for yet unknown words according to Aveni (2019). 
Table 2 presents the assessment level of students' knowledge in Machine shorthand in terms of phrases and derivatives.

\begin{tabular}{lccc}
\hline \multicolumn{1}{c}{ Statements } & $\begin{array}{c}\text { Weighted } \\
\text { Mean }\end{array}$ & SD & Remarks \\
\hline 1. I am familiar in phrases and derivatives. & 3.63 & 0.68 & Often \\
2. I can recognize the derivatives. & 3.56 & 0.73 & Often \\
3. I know how to place the symbol of phrases and & & & \\
$\quad$ derivatives. & 3.67 & 0.71 & Often \\
4. I know how to use the symbol in derivatives. & 3.61 & 0.71 & Often \\
5. I know how to put the symbol accurately. & 3.56 & 0.69 & Often \\
\hline
\end{tabular}

Grand Mean $=3.61$

Population Standard Deviation $=0.5772$

Verbal Interpretation $=$ Satisfactory

Legend:

$\begin{array}{clll}\text { Scale } & \text { Range } & \text { Remarks } & \text { Verbal Interpretation } \\ 5 & 4.20-5.00 & \text { Always } & \text { Very Satisfactory } \\ 4 & 3.40-4.19 & \text { Often } & \text { Satisfactory } \\ 3 & 2.60-3.39 & \text { Sometimes } & \text { Moderately Satisfactory } \\ 2 & 1.80-2.59 & \text { Rarely } & \text { Less Satisfactory } \\ 1 & 1.00-1.79 & \text { Never } & \text { Not Satisfactory }\end{array}$

The weighted mean of $\mathbf{3 . 6 1}$ has a standard deviation of 0.5772 with variance of 0.3332 indicating how the data scores are homogeneous to each other. The Skewness of 0.02 and a Kurtosis of -0.26 shows that the strategic priorities has a fairly symmetrical distribution with a sharp and central peak of score of 1 (minimum) and 4 (maximum) has a verbal interpretation of Satisfactory. This research used 2000 common court stenography words and phrases as the core dataset for training, validation, and testing. Application of canny edge detection provides the detection of edges to provide a better classification of stenographic writings Montalbo, et al. (2019). 
Table 3 presents the assessment level of students' knowledge in Machine shorthand in terms of word abbreviation.

\begin{tabular}{lccc}
\hline \multicolumn{1}{c}{ Statements } & $\begin{array}{c}\text { Weighted } \\
\text { Mean }\end{array}$ & SD & Remarks \\
\hline 1. I am familiar with the word abbreviations. & 3.69 & 0.77 & Often \\
2. I can easily recognize the symbol of & 3.65 & 0.71 & Often \\
$\quad$ abbreviation. & 3.60 & 0.81 & Often \\
3. I can memorize each abbreviation. & 3.78 & 0.80 & Often \\
4. I know more than twenty words abbreviation & 3.49 & 0.71 & Often \\
5. I can easily transcribe the word abbreviations. & &
\end{tabular}

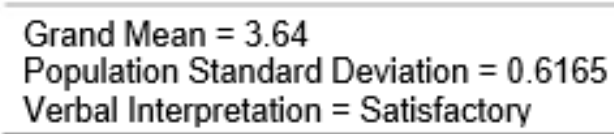

Legend:

$\begin{array}{clll}\text { Scale } & \text { Range } & \text { Remarks } & \text { Verbal Interpretation } \\ 5 & 4.20-5.00 & \text { Always } & \text { Very Satisfactory } \\ 4 & 3.40-4.19 & \text { Often } & \text { Satisfactory } \\ 3 & 2.60-3.39 & \text { Sometimes } & \text { Moderately Satisfactory } \\ 2 & 1.80-2.59 & \text { Rarely } & \text { Less Satisfactory } \\ 1 & 1.00-1.79 & \text { Never } & \text { Not Satisfactory }\end{array}$

The weighted mean of $\mathbf{3 . 6 4}$ has a standard deviation of 0.6165 with variance of 0.3801 indicating how the data scores are homogeneous to each other. The Skewness of 0.02 and a Kurtosis of -0.59 shows that the strategic priorities has a fairly symmetrical distribution with a sharp and central peak of score of 1 (minimum) and 4 (maximum) has a verbal interpretation of Satisfactory. As cited by Kumar, et al. (2017). Shorthand system provides symbols or abbreviations for words and common phrases, which can allow someone well-trained in the system to write as quickly as people speak. Abbreviation methods are alphabet based and use different abbreviating approaches. Several autocomplete programs, standalone or integrated in text editors, based on word lists, also include a shorthand function for frequently-used phrases (). 
Table 4 presents the assessment level of students' knowledge in Machine shorthand in terms of keyboard practices.

Table 4. Assessment level of students' knowledge in Machine shorthand in terms of Keyboard practice

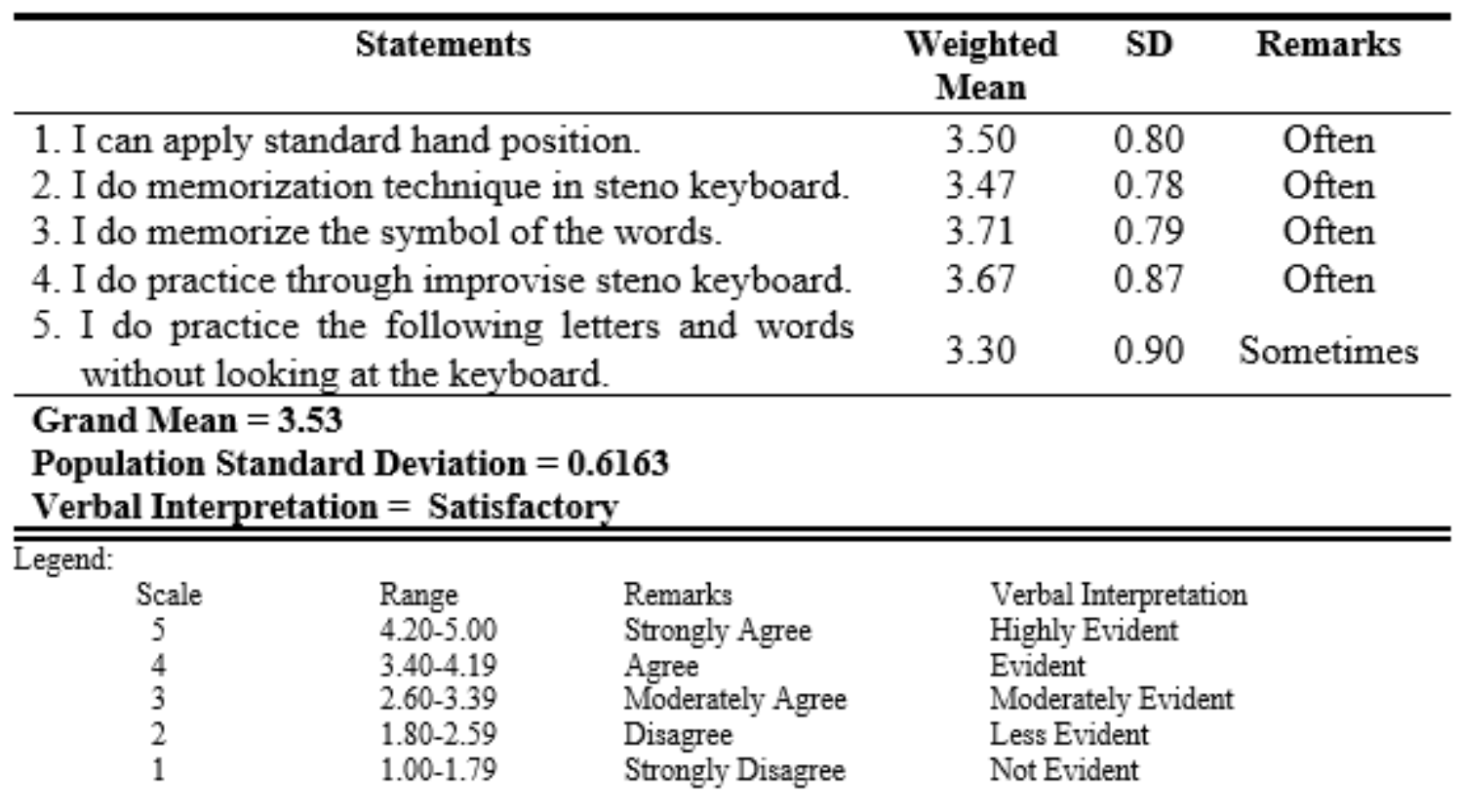

The weighted mean of $\mathbf{3 . 5 3}$ has a standard deviation of 0.6163 with variance of 0.3798 indicating how the data scores are homogeneous to each other. The Skewness of 0.30 and a Kurtosis of -0.05 shows that the strategic priorities has a fairly symmetrical distribution with a sharp and central peak of score of 1 (minimum) and 4 (maximum) has a verbal interpretation of Satisfactory with the result of the present study, a method of generating symbols from a chording keyboard is described. A unique feature of this method is accepting a sequence of chords from the keyboard without either an intervening chord or a requirement that all keys be released between chords according to Skogsrud, et al. (2019). 
Table 5 presents the composite assessment level of students' knowledge in Machine shorthand.

Table 5. Composite assessment level of students' knowledge in Machine shorthand 禹

\begin{tabular}{lccc}
\hline \multicolumn{1}{c}{ Indicators } & $\begin{array}{c}\text { Grand } \\
\text { Mean }\end{array}$ & SD & $\begin{array}{c}\text { Verbal } \\
\text { Interpretation }\end{array}$ \\
\hline Sound pattern & 3.72 & 0.529 & Satisfactory \\
Phrases and derivatives & 3.61 & 0.577 & Satisfactory \\
Word abbreviation & 3.64 & 0.617 & Satisfactory \\
Keyboard practice & 3.53 & 0.616 & Satisfactory \\
\hline
\end{tabular}

Total Mean $=3.63$

Population Standard Deviation $=0.5896$

Verbal Interpretation $=$ Satisfactory

Legend:

$\begin{array}{clll}\text { Scale } & \text { Range } & \text { Remarks } & \\ 5 & 4.20-5.00 & \text { Always } & \text { Verbal Interpretation } \\ 4 & 3.40-4.19 & \text { Often } & \text { Very Satisfactory } \\ 3 & 2.60-3.39 & \text { Sometimes } & \text { Satisfactory } \\ 2 & 1.80-2.59 & \text { Rarely } & \text { Moderately Satisfactory } \\ 1 & 1.00-1.79 & \text { Never } & \text { Less Satisfactory } \\ & & & \text { Not Satisfactory }\end{array}$

With a $(\mathrm{TM}=3.63, \mathrm{PSD}=0.5896)$ the composite assessment level of students' knowledge in Machine shorthand is satisfactory. 
Table 6 presents the extent of students' performance in Machine shorthand with regards to striking speed.

\begin{tabular}{lccc}
\hline \multicolumn{1}{c}{ Statements } & $\begin{array}{c}\text { Weighted } \\
\text { Mean }\end{array}$ & SD & Remarks \\
\hline $\begin{array}{l}\text { 1. I can type a sentence to the given time. } \\
\text { 2. I can type a sentence in standard hand }\end{array}$ & 3.19 & 0.73 & Sometimes \\
$\begin{array}{l}\text { position. } \\
\text { 3. I can transcribe thirty words per minute }\end{array}$ & 3.18 & 0.72 & Sometimes \\
$\quad$ dictation. & 3.96 & 0.79 & Sometimes \\
$\begin{array}{l}\text { 4. I can transcribe a sentence during dictation. } \\
\text { 5. I can type a sentence precisely even have a } \\
\text { time limit. }\end{array}$ & 3.01 & 0.74 & Sometimes \\
\hline
\end{tabular}

Grand Mean $=3.09$

Population Standard Deviation $=\mathbf{0 . 6 3 3 1}$

Verbal Interpretation $=$ Moderately Satisfactory

Legend:

Scale
5
4
3
2
1

$\begin{array}{ll}\text { Range } & \text { Remarks } \\ 4.20-5.00 & \text { Always } \\ 3.40-4.19 & \text { Often } \\ 2.60-3.39 & \text { Sometimes } \\ 1.80-2.59 & \text { Rarely } \\ 1.00-1.79 & \text { Never }\end{array}$

Verbal Interpretation

Very Satisfactory

Satisfactory

Moderately Satisfactory

Less Satisfactory

Not Satisfactory

The weighted mean of $\mathbf{3 . 0 9}$ has a standard deviation of 0.6331 with variance of 0.4008 indicating how the data scores are homogeneous to each other. The Skewness of 0.06 and a Kurtosis of -0.15 shows that the strategic priorities has a fairly symmetrical distribution with a sharp and central peak of score of 1 (minimum) and 4 (maximum) has a verbal interpretation of Moderately Satisfactory. Psychomotor performance of the users' transitions between chords is recorded as distinct from performance relating to chords. A first trial keyboard mapping table from chords to symbols is created, and the effectiveness of that table is measured by applying it to a text corpus and measuring the total psychomotor cost to enter that corpus with that table as mentioned by Rubin, et al. (2018). 
Table 7 presents the extent of students' performance in Machine shorthand with regards to reading comprehension.

\begin{tabular}{|c|c|c|c|c|c|}
\hline \multicolumn{3}{|c|}{ Statements } & $\begin{array}{l}\text { Weighted } \\
\text { Mean }\end{array}$ & SD & Remarks \\
\hline \multicolumn{3}{|c|}{$\begin{array}{l}\text { 1. I do practice my reading skills in transcribing } \\
\text { words. }\end{array}$} & 3.71 & 0.80 & Often \\
\hline \multicolumn{3}{|c|}{ 2. I can easily understand the transcribe words. } & 3.53 & 0.79 & Often \\
\hline \multicolumn{3}{|c|}{ 3. I can read the words in a line continuous. } & 3.56 & 0.74 & Often \\
\hline \multicolumn{3}{|c|}{ 4. I can easily read tape notes. } & 3.55 & 0.74 & Often \\
\hline \multicolumn{3}{|c|}{$\begin{array}{l}\text { 5. I still can read machine shorthand whatever } \\
\text { theory use. }\end{array}$} & 3.27 & 0.79 & Sometimes \\
\hline \multicolumn{6}{|c|}{$\begin{array}{l}\text { Grand Mean }=\mathbf{3 . 5 2} \\
\text { Population Standard Deviation }=\mathbf{0 . 6 4 1 7} \\
\text { Verbal Interpretation = Satisfactory } \\
\end{array}$} \\
\hline \multicolumn{6}{|c|}{ Legend: } \\
\hline $\begin{array}{l}\text { Scale } \\
5 \\
4 \\
3 \\
2 \\
1\end{array}$ & $\begin{array}{l}\text { Range } \\
4.20-5.00 \\
3.40-4.19 \\
2.60-3.39 \\
1.80-2.59 \\
1.00-1.79\end{array}$ & $\begin{array}{l}\text { Remarks } \\
\text { Always } \\
\text { Often } \\
\text { Sometimes } \\
\text { Rarely } \\
\text { Never }\end{array}$ & \multicolumn{3}{|c|}{$\begin{array}{l}\text { Verbal Interpretation } \\
\text { Very Satisfactory } \\
\text { Satisfactory } \\
\text { Moderately Satisfactory } \\
\text { Less Satisfactory } \\
\text { Not Satisfactory }\end{array}$} \\
\hline
\end{tabular}

The weighted mean of $\mathbf{3 . 5 2}$ has a standard deviation of 0.6417 with variance of 0.4117 indicating how the data scores are homogeneous to each other. The Skewness of 0.10 and a Kurtosis of -0.55 shows that the strategic priorities has a fairly symmetrical distribution with a sharp and central peak of score of 1 (minimum) and 4 (maximum) has a verbal interpretation of Satisfactory. In reference to the study of Muijselaar et al. (2019) reading comprehension, reading strategies, reading fluency, vocabulary, and working memory were administered. A structural equation model was constructed to estimate the unique relations between reading strategies and reading comprehension, while controlling for reading fluency, vocabulary, and working memory. The results showed that there was a unique effect of reading strategies on reading comprehension, and also of reading comprehension on reading strategies. 
Table 8 presents the extent of students' performance in Machine shorthand with regards to transcription ability.

\begin{tabular}{lccc}
\hline \multicolumn{1}{c}{ Statements } & $\begin{array}{c}\text { Weighted } \\
\text { Mean }\end{array}$ & SD & Remarks \\
\hline 1. I can transcribe all word by sounds. & 3.51 & 0.76 & Often \\
$\begin{array}{l}\text { 2. I can transcribe all phrases and derivatives in } \\
\quad \text { sentence. }\end{array}$ & 3.43 & 0.69 & Often \\
3. I can transcribe word abbreviation. & 3.58 & 0.81 & Often \\
4. I can transcribe a sentence during dictation. & 3.39 & 0.76 & Often \\
5. I can transcribe 30 words in one minute. & 3.20 & 0.87 & Sometimes
\end{tabular}

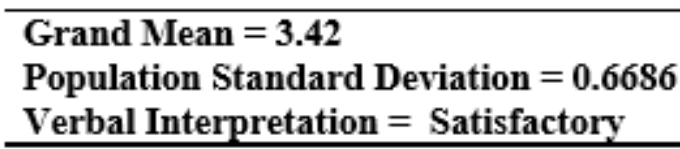

\begin{tabular}{clll}
\hline \hline Legend: & & & \\
Scale & Range & Remarks & Verbal Interpretation \\
5 & $4.20-5.00$ & Always & Very Satisfactory \\
4 & $3.40-4.19$ & Often & Satisfactory \\
3 & $2.60-3.39$ & Sometimes & Moderately Satisfactory \\
2 & $1.80-2.59$ & Rarely & Less Satisfactory \\
1 & $1.00-1.79$ & Never & Not Satisfactory
\end{tabular}

The weighted mean of $\mathbf{3 . 4 2}$ has a standard deviation of 0.6686 with variance of 0.4470 indicating how the data scores are homogeneous to each other. The Skewness of 0.04 and a Kurtosis of -0.06 shows that the strategic priorities has a fairly symmetrical distribution with a sharp and central peak of score of 1 (minimum) and 4 (maximum) has a verbal interpretation of Satisfactory. Virtual keyboard layout combines handwriting recognition with a virtual, graphical, or on-screen keyboard to provide a text input method with relative ease of use. The system allows the user to input text quickly with little or no visual attention from the user. The system supports a very large vocabulary of gesture templates in a lexicon, including practically all words needed for a particular user. In addition, the system utilizes various techniques and methods to achieve reliable recognition of a very large gesture vocabulary. The system supports a very large vocabulary of 
gesture templates in a lexicon, including practically all words needed for a particular user. In addition, the system utilizes various techniques and methods to achieve reliable recognition of a very large gesture vocabulary as claimed by Kristensson, et al. (2014).

Table 9 presents the composite extent of students' performance in Machine shorthand.

\begin{tabular}{|c|c|c|c|c|c|}
\hline \multicolumn{3}{|c|}{ Indicators } & $\begin{array}{l}\text { Grand } \\
\text { Mean }\end{array}$ & SD & $\begin{array}{c}\text { Verbal } \\
\text { Interpretation }\end{array}$ \\
\hline \multicolumn{3}{|c|}{ Striking speed } & 3.09 & 0.633 & Satisfactory \\
\hline \multicolumn{3}{|c|}{ Reading comprehension } & 3.52 & 0.642 & Satisfactory \\
\hline \multicolumn{3}{|c|}{ Transcription ability } & 3.42 & 0.669 & Satisfactory \\
\hline \multicolumn{6}{|c|}{$\begin{array}{l}\text { Total Mean }=\mathbf{3 . 3 4} \\
\text { Population Standard Deviation }=0.5826 \\
\text { Verbal Interpretation = Moderately Satis }\end{array}$} \\
\hline \multicolumn{6}{|l|}{ Legend: } \\
\hline $\begin{array}{l}\text { Scale } \\
5 \\
4 \\
3 \\
2 \\
1\end{array}$ & $\begin{array}{l}\text { Range } \\
4.20-5.00 \\
3.40-4.19 \\
2.60-3.39 \\
1.80-2.59 \\
1.00-1.79\end{array}$ & $\begin{array}{l}\text { Remarks } \\
\text { Always } \\
\text { Often } \\
\text { Sometimes } \\
\text { Rarely } \\
\text { Never }\end{array}$ & & $\begin{array}{l}\text { Verbal I } \\
\text { Very Sat } \\
\text { Satisfact } \\
\text { Moderat } \\
\text { Less Sat } \\
\text { Not Satis }\end{array}$ & $\begin{array}{l}\text { retation } \\
\text { tory } \\
\text { atisfactory } \\
\text { tory } \\
\text { ory }\end{array}$ \\
\hline
\end{tabular}

With a $(\mathrm{TM}=3.34, \mathrm{PSD}=0.5826)$ the composite extent of students' performance in Machine shorthand is moderately satisfactory.

Table 10 presents the students' performance in Machine shorthand in Pre-test and Post-test of the students.

\begin{tabular}{|c|c|c|c|c|c|c|c|c|c|c|}
\hline Variable & $\mathbf{N}$ & Mean & StDev & Yar & Min & Max & Mode & Sk & $\mathbf{K u}$ & VI \\
\hline Pre-test & 113 & 11.805 & 4.571 & 20.890 & 0 & 20 & 13 & -0.04 & -0.48 & LS \\
\hline Post-test & 113 & 21.965 & 6.009 & 36.106 & 3 & 30 & 26 & -1.03 & 0.35 & $\mathrm{~S}$ \\
\hline $\begin{array}{r}\text { DESCRIPT } \\
5 \\
4 \\
3 \\
2 \\
1\end{array}$ & $\overline{\mathrm{ON}}$ & $\begin{array}{l}\text { SC } \\
25 \\
19 \\
13 \\
7-1 \\
0-6\end{array}$ & $\begin{array}{l}\mathrm{ILE} \\
0 \\
4 \\
8\end{array}$ & $\begin{array}{l}\text { VER } \\
\text { Very } \\
\text { Satisf } \\
\text { Mode } \\
\text { Less } \\
\text { Not S }\end{array}$ & $\begin{array}{l}\text { AL INT } \\
\text { atisfacto } \\
\text { ctory (S } \\
\text { ately Sat } \\
\text { tisfacto } \\
\text { tisfactor }\end{array}$ & $\begin{array}{l}\text { ERPRE } \\
\text { ry (VS) } \\
\text { isfactor } \\
\text { y (LS) } \\
\text { (NS) }\end{array}$ & $\begin{array}{l}\text { [ATION } \\
\text { (MS) }\end{array}$ & & & \\
\hline
\end{tabular}


Table 10 presents students' performance in Machine shorthand in Pre-test and post-test, in terms of Pre-test, the weighted mean of $\mathbf{1 1 . 8 0 5}$ has a standard deviation of 4.571 with variance of 20.890 indicating how the data scores are homogeneous to each other. The Skewness of -0.04 and a Kurtosis of -0.48 shows that the strategic priorities has a fairly symmetrical distribution with a sharp and central peak of score of 1 (minimum) and 4 (maximum) has a verbal interpretation of Less Satisfactory. And in terms of Post-test, the weighted mean of $\mathbf{2 1 . 9 6 5}$ has a standard deviation of 6.009 with variance of 36.106 indicating how the data scores are homogeneous to each other. The Skewness of -1.03 and a Kurtosis of 0.35 shows that the strategic priorities has a fairly symmetrical distribution with a sharp and central peak of score of 1 (minimum) and 4 (maximum) has a verbal interpretation of Satisfactory.

Table 11 presents significant difference of the assessment of the sound Machine to the performance.

\begin{tabular}{|c|c|c|c|c|c|c|}
\hline Sample & Mean & StDex & $\begin{array}{c}95 \% \text { CI for } \boldsymbol{\mu} \\
\text { difference }\end{array}$ & $\begin{array}{c}\text { T- } \\
\text { value }\end{array}$ & $\begin{array}{c}\mathbf{P}- \\
\text { value }\end{array}$ & $\begin{array}{c}\text { Verbal } \\
\text { Interpretation }\end{array}$ \\
\hline Pre-test & -10.159 & 6.190 & $(-11.313,-9.006)$ & -17.45 & 0.000 & Significant \\
\hline Post-test & & & & & & \\
\hline
\end{tabular}

Table 11 presents the significant difference of the Assessment of the Sound Machine to the performance of the students in determining the difference of the Assessment of the Machine Shorthand to the performance of the students, the data were statistically treated between the pre-test and post-test that which arrived to the computed value t-test. It shows the computed t-value is -17.45 , with the supported computed pvalue 0.000 and the analysis of Significant.

Based on the data, it is shown that there is a "significant difference of the Assessment of the Machine shorthand to the performance of the students" at 0.05 level of significance. It shows that the null hypothesis stating that "There is no significant difference of the Assessment of the Sound Machine to the performance of the students" is rejected thus the alternative hypothesis is rejected, it can have inferred that there is a "significant" difference between them. 


\section{Conclusions and Recommendations}

This study revealed students' knowledge in Machine Shorthand with a total mean score of 3.63 "Satisfactory"; Students' performance in Machine shorthand, with a total mean score of 3.34 - "Moderately Satisfactory"; Students' performance in Machine shorthand in terms of Pre-test with a mean score of 11.805 has a verbal interpretation of "Less Satisfactory"; And in terms of Post-test with a mean score of 21.965 "Satisfactory".

It was inferred that the performance considering pre-test and post-test, the researcher can conclude that the students progressed adequately as the student's performance in machine shorthand changes from less satisfactory in the pre-test to satisfactory in the post-test but still needs improvement.

Level of significance was found between knowledge and their performance which means the assessment of students' performance was affect for their knowledge on Machine Shorthand. A development of instructional materials shall be proposed for the improvement of students' performance which include learn to operate the machine shorthand through proper keyboard techniques and full understanding of the principles involved in learning.

\section{References}

AVENI, T. (2019). Passive Haptic Learning for Computer Stenography. Retrieve from: https://smartech.gatech.edu

CALMORIN, et. al. (2016). Methods of Research and Thesis Writing. Retrieve from: https://www.academia.edu/

EGER, DON (2011). Theory of Performance. Retrieve from: https://www.webpages.uidaho.edu

KRISTENSSON, P. \& SHUMIN, Z., (2015). Shorthand writing on stylus keyboard. Proceedings of the SIGCHI Conference on Human Factors in Computing Systems. Retrieve from: https://dl.acm.org

KUMAR, P., NARENDRA, T. V., \& VINAY N. A. (2017). International Journal of Advanced Research in Computer Science and Software Engineering. Short Hand Recognition using Canny Edge Detector. Retrieve from: https://www.researchgate.net

LANG, T. (2019). The long and the short of abbreviations. Tom Lang Communications and Training International. Retrieve from: https://europeanscienceediting.eu

MONTALBO, FJ. P., \& BARFEH, DP. (2019). Classification of Stenography using Convolutional Neural Networks and Canny Edge Detection Algorithm. Retrieve from: https://ieeexplore.ieee.org

RUBIN, K., WESTVANG, E., ROSTAD, O., \& (2018). Method of creating a chording keyboard mapping table. Retrieve from: https://patents.patsnap.com 
SKOGSRUD, SS., WESTVANG, E., \& ROSTAD, O. (2019). Method of generating symbols from a chording keyboard. Retrieve from: https://patents.google.com 